\title{
Hedefe Yönelik Kanser İlaç Dizaynında Isı Şok Proteni 90
}

\author{
Heat Shock Protein 90 in Target Spesific Cancer Drug Design
}

\section{Aykut Özgür ${ }^{1}$ İ́sa Gökçe}

${ }^{1}$ Tokat Gaziosmanpaşa Üniversitesi, Artova Meslek Yüksekokulu, Veterinerlik Bölümü, Laborant ve Veteriner Sağlık Programı, Tokat

${ }^{2}$ Tokat Gaziosmanpaşa Üniversitesi, Mühendislik ve Doğa Bilimleri Fakültesi, Genetik ve Biyomühendislik Bölümü, Tokat

\author{
Yazı̧sma Adresi / Correspondence: \\ Dr. Öğr. Üyesi Aykut ÖZGÜR \\ Tokat Gaziosmanpaşa Üniversitesi, Artova Meslek Yüksekokulu, Veterinerlik Bölümü, Laborant ve Veteriner Sağlık Programı, Tokat, Türkiye \\ Tel: +905057513846 E-mail: aykut.ozgur@gop.edu.tr \\ Orcid \\ Aykut Özgür https://orcid.org/0000-0002-4457-1249 \\ İsa Gökçe https://orcid.org/0000-0002-5023-9947 \\ Geliş Tarihi / Received : 14-11-2018 Kabul Tarihi / Accepted : 25-11-2019 Yayın Tarihi/ Online Published: 27-12-2019 \\ Özgür A., Gökçe İ., Hedefe Yönelik Kanser İlaç Dizaynında Isı Şok Proteni 90, \\ J Biotechnol and Strategic Health Res. 2019;3(3):161-169 DOİ: bshr.647101
}

Özet

Isı șok proteini 90 (HSP90) korunmuș bir proteindir ve onkogenik proteinlerin katlanması ve stabilizasyonundan görevlidir. Bundan dolayı HSP90’nın șaperon görevinin inhibisyonu hedefe spesifik kanser tedavisinde önemli bir terapötik strateji olmaktadır. Çok sayıda doğal ve sentetik bileşikler klinik öncesi ve klinik çalışmalarda HSP90 inhibitörü olarak değerlendirilmiştir. Bu çalışmada, HSP90 inhibisyonunun tümörogenezdeki moleküler mekanizmaları ve HSP90 inhibitörlerinin genel özellikleri tartışılacaktır.

Anahtar Isı şok proteinleri, Kanser, Onkoloji, Hücresel Stres

Kelimeler

Abstract

Heat shock protein 90 (HSP90) is conserved chaperone protein which is involved in proper folding and stabilization of oncogenic proteins. Therefore, inhibition of the chaperone function of HSP90 has been significant therapeutic strategy in target specific cancer treatment. Numerous natural and synthetic compounds have been evaluated as potential HSP90 inhibitor in pre-clinical and clinical studies. In this paper, we will discuss the molecular mechanisms of HSP90 inhibition in tumorigenesis and the general properties and structures of the HSP90 inhibitors.

Keywords Heat shock proteins, Cancer, Oncology, Cellular stress 


\section{Giriş}

Kanser genetik faktörlerin, cinsiyet, yaş ve çevresel etmenlerin (radyasyon, beslenme alışkanlıkları, kimyasal ajanlar, stres, vb) etkisiyle kompleks sinyal yolaklarının rol oynadığı bir hastalıktır. Dünya genelinde sık görülen ve mortalitesi en yüksek hastalıklardan biridir. Dünya Sağlık Örgütüne bağlı Uluslararası Kanser Araştırmaları Kurumunun (IARC) verilerine göre, her yıl dünyada 14 milyon insana kanser teşhisi konmakta ve 2018 yılında 9,6 milyon kişi kanserden dolayı hayatını kaybetmiştir. 2030 yılında dünya genelinde 12 milyon kişinin kanser nedeni ile hayatını kaybedeceği öngörülmektedir ${ }^{1}$.

Kanser tedavisinin en önemli ve etkin basamağını kemoterapi oluşturmaktadır. Kanserin gelişiminde ve ilerlemesinde rol oynayan moleküler mekanizmaların aydınlatılması ile hedefe yönelik kanser ilaç dizayn çalışmaları son yıllarda hız kazanmış ve günümüzde çok sayıda ilaç rutin olarak kanser tedavisinde kullanılmaktadır. Bu ilaçların klinik başarıları ile hasta sağ kalımı önemli ölçüde artmış olsa da tedavi başarıları istenilen ölçüde değildir² ${ }^{2}$ Bundan dolayı kanser oluşumunda ve ilerleyen evrelerinde rol oynayan diğer hedef biyomoleküller araştırılmakta ve son yıllarda 1sı şok proteinleri (HSP) hedefe yönelik kanser ilaç dizayn çalışmalarında önemli bir hedef olarak karşımıza çıkmak$\operatorname{tad}^{3} \mathrm{r}^{3-5}$.

HSP'ler evrim boyunca korunmuş önemli bir protein ailesidir ve prokaryotlardan ökaryotlara kadar her canlıda eksprese edilmektedir. HSP'ler hücrede yeni sentezlenmiş proteinlerin katlanması, protein agregasyonunun önlenmesi, proteinlerin stabilizasyonu ve yanlış katlanmış proteinlerin eliminasyonu gibi görevler üstlenmiştir. HSP’ler molekül kütlelerine göre beş ana sınıfa ayrılmaktadırlar: küçük HSP'ler (<40 kDa), HSP60 (60 kDa), HSP70 (70 kDa), HSP90 (90 kDa) ve HSP100 (100 kDa). Her bir IŞP farklı izoformlara sahiptir ve hücrenin farklı bölümlerinde lokalize olmuşlardır ${ }^{5-7}$.

Hücre stres koşullarına (yüksek ateş, oksidatif stres, ağır metaller, UV 1şık, enfeksiyon, radyasyon, tümör oluşumu, vb.) maruz kaldığında, hücrede protein homeostasisinin sağlanması ve hücrenin sağ kalımının desteklenmesi için HSP’lerin ekspresyon seviyelerin de artış görülmektedir. Özellikle kanser hücrelerinde, HSP'lerin bu hücre koruyucu görevleri kötü prognoz ve tedavide kullanılan kemoterapötiklere karşı direnç mekanizmaları ile bağlantılıdır. Literatürde yer alan sayısız klinik öncesi ve klinik çalışmalarda kanserli hücrelerde HSP'lerin ekspresyon seviyelerinin yüksek olduğu belirtilmiştir. Bundan dolayı kanser ilaç dizayn çalışmalarında HSP’ler önemli bir çalışma alanı olmuştur ${ }^{5}$.

Kanserli hücrelerin metabolik hızı normal sağlıklı hücrelere göre oldukça yüksektir. Bu bağlamda kanserli hücrelerin sağ kalım sürelerinin artması ve hücresel bütünlüğün korunması için sağlıklı hücrelere kıyasla daha fazla HSP'lere ihtiyacı vardır. Kanser hücrelerinde metastatik ve anti-apoptotik yolakların aktivasyonunda ve kemoterapötiklere karşı gelişen ilaç direnç mekanizmalarında HSP27, HSP70 ve HSP90 önemli görevler üstlenmektedirler ve ekspresyon seviyeleri sağlıklı hücrelere göre 4-5 kat oranında artmaktadır. Bundan dolayı kanserli hücrelerde HSP27, HSP70 ve HSP90'nın inhibisyonu son yıllarda önemli bir ilaç geliştirme stratejisi olarak klinik öncesi ve klinik çalışmalarda değerlendirilmektedir ${ }^{3,8-10}$. Bu çalışmada, HSP90'nın moleküler seviyede tümörogenezde ki biyolojik rolleri ve HSP90'nın inhibisyonu için geliştirilen inhibitörlerin etki mekanizmaları değerlendirilecektir.

\section{HSP90 VE KANSER}

HSP90 evrim boyunca korunmuş, $90 \mathrm{kDa}$ ağırlığa sahip HSP ailesinin önemli bir üyesidir. Ökaryotik canlılarda en çok eksprese edilen proteinlerden biridir ve eksprese edilen tüm proteinlerin yaklaşı \%1-2'sini HSP90 oluşturmaktadır. Tümör oluşumunda ve diğer stres faktörleri etkin olduğunda HSP90 ekspresyonu \%4-6 seviyelerine çıkabilmektedir. Normal sağlıklı hücrelerde HSP90 protein katlanması ve stabilizasyonu, hücresel sinyal iletimi ve intraselüler transportta görev almaktadır ${ }^{3,10,11}$. 
HSP90 dört farklı izoforma sahiptir: HSP90a, HSP90ß, TRAP1 (TNF receptor-associated protein 1) ve GRP94 (Glucose regulated protein 94). HSP90a ve HSP90 $\beta$ sitozolde, TRAP1 mitokondride ve GRP94 endoplazmik retikulumda lokalize olmuşlardır. Hücrede HSP90a indüktif (induced-indüklenebilir) ve HSP90 $\beta$ konstitif (constitutive-devamlı) şekilde eksprese edilmektedir. HSP90a ve HSP90ß, $25 \mathrm{kDa}$ N-terminal domain (NTD), $55 \mathrm{kDa}$ middle domain (MD) ve $10 \mathrm{kDa}$ C-terminal domain (CTD) olmak üzere korunmuş üç adet domainden oluşmaktadır. HSP90 NTD ATP bağlanma bölgesine sahiptir ve ATP'nin hidroliz enerjisi HSP90'nın protein katlanma prosesi için gereklidir ${ }^{3,10}$.

HSP90 dimerik yapıda bir proteindir ve ATP'nin ortamda bulunmadığı durumlarda, NTD açık konformasyondadir (open conformation) ve yapisal olarak "V" harfine benzemektedir. HOP ve CDC37 ko-şaperon proteinleri NTD’nin bu açık konformasyonda kalmasını sağlar ve HSP90'nın ATPaz prosesini inhibe ederler. Katlanması gereken proteinler açık konformasyondaki HSP90'nın hidrofobik bölgeleri ile etkileşime girer ve HSP90 açık konformasyondan kapalı konformasyona geçerek HSP90'nın dimerleşme süreci başlar. Bu konformasyon değişikliğinde NTD'de ATPaz aktivitesi gerçekleşir ve p23 ko-şaperon proteini NTD’ye bağlanarak katlanmış olan proteinlerin olgunlaşmasını ve stabilizasyonu sağlamaktadır. ATP’nin ADP’ye hidrolizi sonrasında NTD'de kapak bölgesi açılır ve HSP90 tekrar açık konformasyona geçiş yapmaktadır. Protein katlanma sürecinde HSP90'daki bu döngü tekrar başlamaktadır ${ }^{3,10,12}$.

Kanser hücreleri; sınırsız hücre bölünmesi, apoptotik yolakların inibisyonu, yakın/uzak dokulara yaylım gösterme, büyüme faktörlerinin ekspresyon seviyelerinin artması ve kan damarları oluşumunu hızlandırarak oksijen ve beslenme gereksinimi gidermesi gibi bir takım karakteristik özellikleri taşımaktadır. Bu biyolojik süreçlerin gerçekleşmesi için kanserli hücrede transkripsiyonel faktörler, tirozin kinaz reseptörleri, hücre döngüsü düzenleyicileri (cell cycle regulators), büyüme faktörleri ve diğer bazı önemli sinyal proteinleri önemli görevler üstlenmektedir ${ }^{13-15}$. Bu proteinlerin katlanmasindan ve stabilizasyonundan sorumlu şaperon protein HSP90'dır. Bu nedenle kanserli hücrelerde HSP90'nın aktivitesinin inhibisyonu önemli bir tedavi stratejisi olarak kabul edilmiştir. Özellikle kanser hücrelerinde HSP90'nın ATP hidroliz mekanizmasını inhibe etmek için, ATP ile yarışan moleküllerin dizaynı (NTD inhibitörleri) ve HSP90'nın dimerleşmesinin inhibisyonu için CTD’yi hedef alan moleküllerin dizaynı (CTD inhibitörleri) son yıllarda önemli bir tedavi yaklaşımı olarak klinik öncesi ve klinik çalışmalarda değerlendirilmektedir ${ }^{3,10}$. Günümüzde FDA'dan onaylı bir HSP90 inhibitörü yoktur. Fakat birçok HSP90 inhibitörünün farklı kanserli hastalar üzerinde klinik çalışmaları devam etmektedir ve geleceğe dair olumlu sonuçlar alınmıştır.

\section{HSP90 NTD İNHİBITTÖRLERİ \\ Geldanamisin Türevi İnhibitörler}

Geldanamisin ilk HSP90 inhibitörü olarak literatürdeki yerini almıştır. Geldanamisin Streptomyces hygroscopicus dan izole edilen benzokinon ansamisin türevi doğal antibiyotik özellikte bir bileşiktir. Geldanamisin HSP90 NTD'deki ATP bağlanma bölgesine yüksek afinite ile bağlanmakta ve ATPaz prosesini inhibe etmektedir. 1990'lı yılların başında NCI-60 kanser hücre hatlarında yapılan çalışmalarda anti-kanser özelliği belirlenmiştir. Nanomolar konsantrasyondaki geldanamisinin mutant B-Raf, Akt, v-Src, p53, CDK4, Met, survivin, Bcr-Abl, telomeraz ve HIF-1'i inhibe ettiği belirlenmiştir. Bu olumlu biyolojik özelliklerinin yanı sıra suda çözünmemesi, stabilitesinin düşük olması ve karaciğerde yüksek toksiste yarattığı için geldanamisin klinik çalışmalarda değerlendirilmemiştir16,17. Bundan dolayı farklı geldanamisin türeleri (17-AAG, 7-DMAG, IPI-504) dizayn edilmiş ve klinik çalışmalarda değerlendirilmiştir (Tablo-1). 17-AAG (17-alil-17-demetoksigeldanamisin) (tanespimycin-KOS-953) ilk sentetik geldanamisin türevi HSP90 inhibitörüdür. 17-AAG kanser hücrelerinde kolaylıkla lokalize olabilmekte ve HSP90'nın ATPaz aktivitesini bloklamaktadır. 17-AAG; HER-2 
(meme kanseri), Ras-Raf-MEK-ERK1/2 ve PI3K-Akt/PKB (kolon ve ovaryum kanseri), Akt ve Erk (Hondkin lenfoma), JAK-STAT, MAPK ve PI3K/Akt (Lösemi) yolaklarını inhibe etmektedir ${ }^{18-21}$. Ayrica multipl miyelomlu hastalar üzerinde klinik Faz-III çalışmaları devam etmektedir ${ }^{22}$. Geldanamisin ile benzer olarak sudaki çözünürlügünün az olması ve organik çözücülerde çözünmesinden dolayı intravenöz olarak hastaya verilmesinde ki olumsuzlar ve ilaç taşıyıcı sistemlere ihtiyaç duyulması klinik çalışmalarda 17-AAG'yi zorlayan en önemli noktalardır. Geldanamisin ve 17-AAG de saptanan bu olumsuz biyolojik ve kimyasal özellikler sonrasında suda çözünen ilk sentetik HSP90 inhibitörü olan geldanamisin türevi 17-DMAG (17-dimetillaminoetilamino-17-demetoksigeldanamisin) (alvespimycin) dizayn edilmiştir ${ }^{3}$. 17-DMAG birçok kanser türünde anti-proliferativ etki göstermesine ek olarak hücrelerde yüksek biyoalım ve dağılım göstermesi, yavaş metabolize olması ve plazma proteinleri ile düşük seviyede ilişkide olması 17-DMAG’yi ön plana çıkaran özellikleridir. 17-DMAG lösemi hücrelerinde IKK ve NF-кB'yi, lenfoma hücrelerinde ise Akt, c-Myc, c-RAF ve CDK4'yi inhibe ederek kanser hücrelerini apoptoza sürüklemektedir23-26. Bir diğer suda çözünen sentetik geldanamisin türevi HSP90 inhibitörü IPI-504 (17-allylamino-17-demethoxygeldanamisin hydroquinone hydrochloride) (retaspimycin)'dür. IPI-504 lösemi, küçük hücreli olmayan akciğer kanseri, meme kanseri, yumuşak doku sarkomları, multipl miyelom ve melanom da anti-kanser özellik göstermektedir. IPI-504'ün klinik çalışmaları özellikle gastrointestinal sistem tümörleri (GIST) üzerinde gerçekleşmektedir. IPI-504 GIST hücrelerinde KIT’i inaktif ederek hücrelerin proliferasyonunu sekteye uğratmaktadır ${ }^{3,27,28}$.

\begin{tabular}{|c|c|c|c|}
\hline İnhibitör & Yapısı & Klinik Çalışmalar & Durumu \\
\hline 17-AAG & & $\begin{array}{c}\text { Lösemi } \\
\text { Lenfoma } \\
\text { Tiroid Kanseri } \\
\text { Solid Tümörler } \\
\text { Meme Kanseri } \\
\text { Melanom } \\
\text { Prostat Kanseri } \\
\text { Pankreas Kanseri } \\
\text { Ovaryum Kanser } \\
\text { Multipl Miyelom }\end{array}$ & $\begin{array}{l}\text { Faz-1/2 } \\
\text { Faz-2 } \\
\text { Faz-2 } \\
\text { Faz-1 } \\
\text { Faz-2 } \\
\text { Faz-2 } \\
\text { Faz-2 } \\
\text { Faz-2 } \\
\text { Faz-2 } \\
\text { Faz } 2 / 3\end{array}$ \\
\hline 17-DMAG & & $\begin{array}{c}\text { Lenfoma } \\
\text { Lösemi } \\
\text { Meme Kanseri }\end{array}$ & $\begin{array}{c}\text { Faz-1 } \\
\text { Faz-1 } \\
\text { Faz-1/2 }\end{array}$ \\
\hline IPI-504 & & $\begin{array}{c}\text { Akciğer Kanseri } \\
\text { Prostat Kanseri } \\
\text { Solid Tümörler } \\
\text { Meme Kanseri } \\
\text { Liposarkoma } \\
\text { Melanom } \\
\text { Multipl Miyelom } \\
\text { GIST } \\
\text { Lösemi }\end{array}$ & $\begin{array}{l}\text { Faz-1/2 } \\
\text { Faz-2 } \\
\text { Faz-1 } \\
\text { Faz-1/2 } \\
\text { Faz-2 } \\
\text { Faz-2 } \\
\text { Faz-1 } \\
\text { Faz-1/3 } \\
\text { Faz-1 }\end{array}$ \\
\hline
\end{tabular}




\section{Pürin Türevi İnhibitörler}

BIIB021 (CNF 2024), MPC-3100, Debio 0932 ve PU-H71 pürin halkası içeren yeni nesil HSP90 NTD inhibitörleridir (Tablo-2). Bu moleküller yüksek afinite ile HSP90 NTD’ye bağlanarak ATPaz sürecinin inhibisyonuna yol açmaktadirlar ${ }^{3}$. BIIB021 oral yolla alınabilen ve sentetik HSP90 NTD inhibitörlerinden ilk klinik çalışmalara giren bileşiktir. BIIB021; HER-2, Akt ve Raf-1'in degredasyonunu sağlayarak nanomolar konsantrasyonlarda meme kanseri, GIST ve lösemi hücrelerinde anti-kanser özellik göstermektedir ${ }^{29,30}$. Bir diğer oral yolla alınabilen HSP90 NTD inhibitörü Debio 0932'dir. Debio 0932 lösemi, küçük hücreli olmayan akciğer kanseri ve meme kanserinde PI3K/
AKT ve RAF/MEK/ERK sinyal yolaklarını inhibe ederek hücreleri apoptoza sürüklemektedir ${ }^{3,10}$. PU-H71 meme kanseri, B-hücreli lenfoma, karaciğer kanseri ve lösemi tedavisi için Memorial Sloan-Kettering Kanser Merkezi tarafından apoptoz indükleyici HSP90 NTD inhibitörü olarak tasarlanmıştır. PU-H71 yüksek afinite ile HSP90a ve GRP94'e bağlanır ve katlanmamış protein cevabı (UPR/ unfolded protein response)'nı aktive ederek kanser hücrelerinde apoptozu tetikleyerek hücre proliferasyonunu inhibe etmektedir. Ayrıca 124I işaretli PU-H71 tümör görüntülenmesi amacıyla pozitron emisyon tomografisi (PET) için dizayn edilmiştir ${ }^{31-33}$.

\begin{tabular}{|c|c|c|c|}
\hline İnhibitör & Yap1s1 & Klinik Çalışmalar & Durumu \\
\hline BIIB021 & & $\begin{array}{c}\text { Solid Tümörler } \\
\text { Meme Kanseri } \\
\text { GIST } \\
\text { Lösemi }\end{array}$ & $\begin{array}{c}\text { Faz-1 } \\
\text { Faz-1-2 } \\
\text { Faz-2 } \\
\text { Faz-1 }\end{array}$ \\
\hline MPC-3100 & & Solid Tümörler & Faz-1 \\
\hline Debio 0932 & & $\begin{array}{l}\text { Akciğer Kanseri } \\
\text { Lenfoma }\end{array}$ & $\begin{array}{l}\text { Faz-1 } \\
\text { Faz-1 }\end{array}$ \\
\hline PU-H71 & & $\begin{array}{l}\text { Meme Kanseri } \\
\text { Lenfoma } \\
\text { Solid Tümör } \\
\text { Lenfoma }\end{array}$ & $\begin{array}{l}\text { Faz-1 } \\
\text { Faz-1 } \\
\text { Faz-1 } \\
\text { Faz-1 }\end{array}$ \\
\hline
\end{tabular}




\section{Pirazol Türevi İnhibitörler}

STA-9090, AUY-922 ve SNX-5422 yapisinda pirazol halkas1 içeren HSP90 NTD inhibitörleridir (Tablo-3). STA-9090 HSP90 NTD’ye yüksek afinite ile bağlanarak ATPaz prosesini inhibe etmesinin yanı sıra p23-HSP90 etkileşiminde ara-yüz inhibitörü olarak görev alarak kanserli hücrelerde c-Kit, EGFR, Akt, ERBB2, IGF-1R, STAT3, STAT5, Jak1, Jak2, HIF-1a, HER2, CDC2 ve c-Met'i inaktif ederek hücre proliferasyonunu bloklamaktadır ${ }^{34,35}$. AUY-922 suda çözünebilen ve oral olarak uygulanabilen yeni nesil HSP90 inhibitörüdür. AUY-922; HER-2, Akt, timidilat sentaz,
CTD4, ERBB2, CRAF, EGFR, fosfo-AKT/total AKT ve hipoksi ile indüklenebilir faktör-1 (HIF-1)'in stabilizasyonunu engelleyerek, küçük hücreli olamayan akciğer kanseri, meme kanseri, kolon kanseri, prostat kanseri, GIST ve miyelomlarda anti-kanser özellik göstermektedir ${ }^{36-39}$. Suda çözünen ve oral yolla uygulanabilen bir inhibitör olan SNX-5422 HSP90 ATPaz sürecini inhibe ederek özellikle solid tümörlerde ve lenfomalarda potansiyel anti-kanser özellik göstermektedir ${ }^{40,41}$. Günümüzde STA-9090, AUY922 ve SNX-5422'nin birçok kanser türünde klinik çalışmaları devam etmektedir.

\begin{tabular}{|c|c|c|c|}
\hline İnhibitör & Yap1s1 & Klinik Çalışmalar & Durumu \\
\hline STA-9090 & & $\begin{array}{c}\text { Karaciğer Kanseri } \\
\text { Prostat Kanseri } \\
\text { Özefagus Kanseri } \\
\text { Meme Kanseri } \\
\text { Kolon ve Rektal Kanser } \\
\text { GIST } \\
\text { Akciğer Kanseri } \\
\text { Lösemi } \\
\text { Multipl Miyelom } \\
\text { Over Kanseri }\end{array}$ & $\begin{array}{c}\text { Faz-1 } \\
\text { Faz-2 } \\
\text { Faz-2 } \\
\text { Faz-2 } \\
\text { Faz-2 } \\
\text { Faz-2 } \\
\text { Faz-1/2 } \\
\text { Faz-1 } \\
\text { Faz-1 } \\
\text { Faz-1/2 }\end{array}$ \\
\hline AUY-922 & & $\begin{array}{c}\text { Pankreas Kanseri } \\
\text { GIST } \\
\text { Akciğer Kanseri } \\
\text { Lenfoma } \\
\text { Meme Kanseri } \\
\text { Kolon Kanseri }\end{array}$ & $\begin{array}{c}\text { Faz-2 } \\
\text { Faz-2 } \\
\text { Faz-1/2 } \\
\text { Faz-2 } \\
\text { Faz-1/2 } \\
\text { Faz-1 }\end{array}$ \\
\hline SNX-5422 & & $\begin{array}{c}\text { Lösemi } \\
\text { Meme Kanseri } \\
\text { Akciğer Kanseri } \\
\text { Lenfoma } \\
\text { Solid Tümörler }\end{array}$ & $\begin{array}{c}\text { Faz-1/2 } \\
\text { Faz-1/2 } \\
\text { Faz-1 } \\
\text { Faz-1 } \\
\text { Faz-1 }\end{array}$ \\
\hline
\end{tabular}




\section{HSP90 CTD İNHİBİTÖRLERI}

HSP90'nın şaperon aktivitesini yerine getirmek için ATP hidrolizinden sonraki en önemli süreç dimerik bir protein olan HSP90 CTD'nin dimerleşme prosesidir. Bundan dolayı HSP90 CTD’nın dimerleşme bölgesini hedefleyen moleküller dizaynı da son yıllarda HSP90'nın inhibisyonu için diğer bir strateji olarak çalışılmaktadır3.

\section{(-)-EGCG}

(-)-EGCG ((-)-Epigallokateşin-3-gallat) yeşil çaydan ekstrakte edilen doğal antioksidan özellikte bir bileşiktir (Tablo-4). HSP90 NTD inhibitörlerinden farklı olarak HSP90 CTD’ye yüksek afinite ile bağlanarak HSP90'nın dimerleşmesini bloke eder ve böylelikle farklı sinyal yolaklarında görev yapan onkogenik proteinlerin katlanmasını, stabilizasyonu ve maturasyonunu inhibe etmektedir. Klinik öncesi ve klinik çalışmalar (-)-EGCG’nin güçlü antioksidan ve anti-kanser etkilere sahip olduğunu göstermiştir. Farklı birçok kanser türlerinde in vitro, in vivo modellerde ve klinik faz çalışmaların da anti-kanser etkileri gösterilmiş ve özellikle (-)-EGCG etkisiyle değişik apoptotik yolakların aktive olduğu belirlenmiştir ${ }^{42-44}$. Prostat kanserli hücrelerde (-)-EGCG’nin EGFR (epidermal büyüme faktor reseptorü) aktivitesini inhibe ettiği birçok çalışmada rapor edilmiştir. EGFR'nin fosforillenerek aktivasyonu, MAPK (mitogen aktivated kinase pathway) ve PI3K/AKT yolakla- rının aktivasyonunu sağlamaktadır. MAPK ve PI3K/AKT yolakları prostat kanserinde başlıca antiapoptotik ve tümör gelişimini tetikleyici etki yapan mekanizmalarda görev almaktadır. (-)-EGCG prostat kanserli hücrelerde fosforile olmuş PI3K ve AKT seviyelerini düşürerek apoptozu indükler ve kanser hücre proliferasyonunu ciddi oranda azaltmaktadır. Ayrıca (-)-EGCG’nin pro-apoptotik (Bax, Bak) proteinlerin ekspresyonunu arttırdığı ve anti-apoptotik (Bcl-2, Bcl-xL) proteinleri ekspresyonunu azalttığ1, NF-kB sinyal yolağını bloke ettiği, IAP (inhibitors of apoptosis proteins) seviyelerini azalttığ 1 ve bunların bir sonucu olarak kaspaz-3 ve kaspaz-6 aktivasyonunu arttırdığı belirlenmiştir. ${ }^{45,46} .2012$ yllında (-)-EGCG’nin prostat kanserli hastalar üzerinde ki Faz-2 çalışmaları başarıyla sonuçlanmıştır ve Faz-3 çalışmaları devam etmektedir (www.clinicaltrials.gov). (-)-EGCG prostat kanseri ile benzer şekilde EGFR'nin fosforillenerek aktive olmasını ve PI3K/AKT ve MAPK yolaklarını inhibe ederek apoptozu indüklemekte ve meme kanserli hücrelerin proliferasyon seviyesini ciddi oranda azaltmaktadır ${ }^{47}$. Ayrıca metastatik karakterli meme kanseri hücre hatlarında yapılan çalı̧̧malarda, (-)-EGCG HGF (hepatocyte growth factor) /MET yolağını sekteye uğratarak meme kanserli hücrelerin proliferasyonunu ve invazyon potansiyelini minumuma düşürmektedir ${ }^{48} .2017$ yllında EGCG’nin meme kanserli hastalar üzerinde ki Faz2 çalışmaları başarıyla sonuçlanmıştır.

\begin{tabular}{|c|c|c|c|}
\hline İnhibitör & Yapis1 & Klinik Çalışmalar & Durumu \\
\hline$(-)-E G C G$ & & $\begin{array}{c}\text { Serviks Kanseri } \\
\text { Prostat Kanseri } \\
\text { Kolon Kanseri } \\
\text { Akciğer Kanseri } \\
\text { Meme Kanseri }\end{array}$ & $\begin{array}{l}\text { Faz-2 } \\
\text { Faz-2 } \\
\text { Faz-2 } \\
\text { Faz-2 } \\
\text { Faz-2 }\end{array}$ \\
\hline
\end{tabular}




\section{Tartışma}

HSP90 onkogenik proteinlerin katlanması ve stabilizasyonunun sağlanmasında görevli HSP şaperon protein ailesinin en önemli üyelerinden biridir. Bu bağlamda HSP90 şaperon aktivitesinin inhibisyonu, hedefe yönelik kanser ilacı geliştirmesi çalışmalarında önemli bir yaklaşımdır. Farklı kanser türlerinde klinik öncesi ve klinik çalışmalarda çok sayıda ilaç adayı molekülün HSP90 inhibisyon potansiyeli değerlendirilmektedir. Günümüzde FDA'dan onaylı rutin kanser tedavisine giren bir HSP90 inhibitörü ilaç yoktur. Fakat klinik çalışmalardan elde edilen olumlu sonuçlar ve kanser hücrelerinde HSP90 inhibitörleri ile yapılan moleküler düzeydeki çalışmalardan elde edilen veriler ışığında yakın zamanda FDA'dan onaylı HSP90 inhibitörlerinin olacağı umut edilmektedir. 


\section{Journal of BSHR 2019;3(3):161-169}

\section{Kaynaklar}

1. Bray F, Ferlay J, Soerjomataram I, et al. Global cancer statistics 2018: GLOBOCAN estimates of incidence and mortality worldwide for 36 cancers in 185 countries. CA Cancer J Clin 2018; 68:394-424.

2. Ramsay RR, Popovic-Nikolic MR, Nikolic K, et al. A perspective on multi-target drug discovery and design for complex diseases. Clin Transl Med 2018; 7:3.

3. Ozgur A, Tutar Y. Heat Shock Protein 90 Inhibition in Cancer Drug Discovery: From Chemistry to Futural Clinical Applications. Anticancer Agents Med Chem 2016; 16:280-290.

4. Gümus M, Ozgur A, Tutar L, et al. Design, Synthesis, and Evaluation of Heat Shock Protein 90 Inhibitors in Human Breast Cancer and Its Metastasis. Curr Pharm Biotechnol 2016; 17:1231-1245.

5. Tutar L, Tutar Y. Heat shock proteins; an overview. Curr Pharm Biotechnol 2010; 11:216222 .

6. Ciocca DR, Calderwood SK. Heat shock proteins in cancer: diagnostic, prognostic, predictive, and treatment implications. Cell Stress Chaperones 200; 10:86-103.

7. Neckers L, Workman P. Hsp 90 molecular chaperone inhibitors: are we there yet? Clin Cancer Res 2012; 18: 64-76.

8. Wu J, Liu T, Rios Z, et al. Heat Shock Proteins and Cancer. Trends Pharmacol Sci 2017; 38:226-256.

9. Jego G, Hazoumé A, Seigneuric R, et al. Targeting heat shock proteins in cancer. Cancer Lett 2013; 332:275-285.

10. Ozgur A, Tutar Y. Heat Shock Protein 90 Inhibitors in Oncology. Curr Proteomics 2014; 11: $2-16$.

11. Usmani SZ, Bona R, Li Z. 17 AAG for HSP90 inhibition in cancer--from bench to bedside. Curr Mol Med 2009; 9:654-664.

12. Dixit A, Verkhivker GM. Probing molecular mechanisms of the Hsp90 chaperone: biophysical modeling identifies key regulators of functional dynamics. PLoS One 2012;7. 10.1371/ journal.pone.0037605.

13. Kim KW, Lee SJ, Kim WY, et al. How Can We Treat Cancer Disease Not Cancer Cells? Cancer Res Treat 2017; 49:1-9.

14. Cree IA. Cancer biology. Methods Mol Biol 2011;731:1-11.

15. Mazurek S, Grimm H, Wilker S, et al. Metabolic characteristics of different malignant cancer cell lines. Anticancer Res 1998;18:3275-3282.

16. Li YP, Chen JJ, Shen JJ, et al. Synthesis and biological evaluation of geldanamycin analogs against human cancer cells. Cancer Chemother Pharmacol 2015; 75:773-782.

17. Hadden MK, Lubbers DJ, Blagg BS. Geldanamycin, radicicol, and chimeric inhibitors of the Hsp90 N-terminal ATP binding site. Curr Top Med Chem 2006; 6: 1173-1182.

18. Modi S, Stopeck A, Linden H, et al. HSP90 inhibition is effective in breast cancer: a phase II trial of tanespimycin (17-AAG) plus trastuzumab in patients with HER2-positive metastatic breast cancer progressing on trastuzumab. Clin Cancer Res 2011; 17:5132-5139.

19. Hostein I, Robertson D, DiStefano F, et al. Inhibition of signal transduction by the Hsp90 inhibitor 17-allylamino-17-demethoxygeldanamycin results in cytostasis and apoptosis. Cancer Res 2001; 61:4003-4009.

20. Georgakis GV1, Li Y, Rassidakis GZ, et al. Inhibition of heat shock protein 90 function by 17-allylamino-17-demethoxy-geldanamycin in Hodgkin's lymphoma cells down-regulates Akt kinase, dephosphorylates extracellular signal-regulated kinase, and induces cell cycle arrest and cell death. Clin Cancer Res 2006; 12:584-590.

21. 2Al Shaer L, Walsby E, Gilkes A, et al. Heat shock protein 90 inhibition is cytotoxic to primary AML cells expressing mutant FLT3 and results in altered downstream signalling. $\mathrm{Br} J$ Haematol 2008; 141:483-493.

22. Usmani SZ, Bona R, Li Z. 17 AAG for HSP90 inhibition in cancer--from bench to bedside. Curr Mol Med 2009; 9:654-664.

23. Holzbeierlein JM, Windsperger A, Vielhauer G. Hsp90: a drug target? Curr Oncol Rep 2010; 12:95-101.

24. Zagouri F, Sergentanis TN, Chrysikos D, et al. Hsp90 inhibitors in breast cancer: a systematic review. Breast 2013; 22:569-578.

25. Hertlein E, Wagner AJ, Jones J, et al. 17-DMAG targets the nuclear factor-kappaB family of proteins to induce apoptosis in chronic lymphocytic leukemia: clinical implications of HSP90 inhibition. Blood 2010; 116:45-53.
26. Rao R, Lee P, Fiskus W, et al. Co-treatment with heat shock protein 90 inhibitor 17-dimethylaminoethylamino-17-demethoxygeldanamycin (DMAG) and vorinostat: a highly active combination against human mantle cell lymphoma (MCL) cells. Cancer Biol Ther 2009; 8:1273-1280.

27. Floris $G$, Debiec-Rychter M, Wozniak A, et al. The heat shock protein 90 inhibitor IPI-504 induces KIT degradation, tumor shrinkage, and cell proliferation arrest in xenograft models of gastrointestinal stromal tumors. Mol Cancer Ther 2011; 10:1897-1908.

28. Fletcher JA, Rubin BP. KIT mutations in GIST. Curr Opin Genet Dev 2007; 17:3-7.

29. Lundgren $K$, Zhang H, Brekken J, et al. BIIB021, an orally available, fully synthetic small-molecule inhibitor of the heat shock protein Hsp90. Mol Cancer Ther 2009; 8:921-929.

30. De Mattos-Arruda L, Cortes J. Breast cancer and HSP90 inhibitors: is there a role beyond the HER2-positive subtype? Breast 2012; 21:604-607.

31. Caldas-Lopes E, Cerchietti L, Ahn JH, et al. Hsp90 inhibitor PU-H71, a multimodal inhibitor of malignancy, induces complete responses in triple-negative breast cancer models. Proc Natl Acad Sci USA 2009; 106:8368-8373.

32. Garcia-Carbonero R, Carnero A, Paz-Ares L. Inhibition of HSP90 molecular chaperones: moving into the clinic. Lancet Oncol 2013; 14:358-369.

33. Gallerne C, Prola A, Lemaire C. Hsp90 inhibition by PU-H71 induces apoptosis through endoplasmic reticulum stress and mitochondrial pathway in cancer cells and overcomes the resistance conferred by Bcl-2. Biochim Biophys Acta 2013;1833:1356-1366.

34. Wang Y, Trepel JB, Neckers LM, et al. STA-9090, a small-molecule Hsp90 inhibitor for the potential treatment of cancer. Curr Opin Investig Drugs 2010; 11:1466-1476.

35. Shimamura T, Perera SA, Foley KP, et al. Ganetespib (STA-9090), a nongeldanamycin HSP90 inhibitor, has potent antitumor activity in in vitro and in vivo models of non-small cell lung cancer. Clin Cancer Res 2012; 18:4973-4985.

36. Eccles SA, Massey A, Raynaud FI, et al. NVP-AUY922: a novel heat shock protein 90 inhibitor active against xenograft tumor growth, angiogenesis, and metastasis. Cancer Res 2008; 68:2850-2860.

37. Lee KH, Lee JH, Han SW, et al. Antitumor activity of NVP-AUY922, a novel heat shock protein 90 inhibitor, in human gastric cancer cells is mediated through proteasomal degradation of client proteins. Cancer Sci 2011; 102:1388-1395.

38. Stingl L, Stühmer T, Chatterjee M, et al. Novel HSP90 inhibitors, NVP-AUY922 and NVP$B E P 800$, radiosensitise tumour cells through cell-cycle impairment, increased DNA damage and repair protraction. Br J Cancer 2010; 102:1578-1591.

39. Garon EB, Finn RS, Hamidi H, et al. The HSP90 inhibitor NVP-AUY922 potently inhibits non-small cell lung cancer growth. Mol Cancer Ther 2013; 12:890-900.

40. Rajan A, Kelly RJ, Trepel JB, et al. A phase I study of PF-04929113 (SNX-5422), an orally bioavailable heat shock protein 90 inhibitor, in patients with refractory solid tumor malignancies and lymphomas. Clin Cancer Res 2011; 17:6831-6839.

41. Reddy N, Voorhees PM, Houk BE, et al. Phase I trial of the HSP90 inhibitor PF-04929113 (SNX5422) in adult patients with recurrent, refractory hematologic malignancies. Clin Ly mphoma Myeloma Leuk 2013; 13:385-391.

42. Hao H, Naomoto Y, Bao X, et al. HSP90 and its inhibitors. Oncol Rep 2010; 23:1483-1492.

43. Singh BN, Shankar S, Srivastava RK. Green tea catechin, epigallocatechin-3-gallate (EGCG): mechanisms, perspectives and clinical applications. Biochem Pharmacol 2011; 82:1807-1821.

44. Yin Z, Henry EC, Gasiewicz TA. (-)-Epigallocatechin-3-gallate is a novel Hsp90 inhibitor. Biochemistry 2009; 48:336-345.

45. Johnson JJ, Bailey HH, Mukhtar H. Green tea polyphenols for prostate cancer chemoprevention: a translational perspective. Phytomedicine 2010; 17:3-13.

46. Yalcin AS, Yllmaz AM, Altundağ EM, et al. Kurkumin, Kuersetin ve Cay Kateșinlerinin Anti-Kanser Etkileri. Marmara Pharm J 2017; 21:19-29.

47. Pan X, Zhao B, Song Z, et al. Estrogen receptor- $\alpha 36$ is involved in epigallocatechin-3-gallate induced growth inhibition of ER-negative breast cancer stem/progenitor cells.J Pharmacol Sci 2016; 130:85-93.

48. Bigelow RL, Cardelli JA. The green tea catechins, (-)-Epigallocatechin-3-gallate (EGCG) and (-)-Epicatechin-3-gallate (ECG), inhibit HGF/Met signaling in immortalized and tumorigenic breast epithelial cells. Oncogene 2006; 25:1922-1930. 